\title{
Editorial
}

\section{EDITORIAL: Learning Technologies in the Era of a Global Pandemic}

\author{
Betül C. Czerkawski \\ Editor, ITLT
}

\begin{abstract}
Since early 2020 , learning technologies have been tested by millions of students, teachers, and parents from all levels of education throughout the globe. many educators discussed learning losses, the inability of online learning to mimic real life learning environments, technological glitches, or the boring user interface of Zoom meetings. On the other hand, if the COVID-19 pandemic had happened 20-25 years ago, students would have completely lost touch with their peers and would not have attended any school for more than a year. In this issue, we have two interesting articles that will guide us as we evaluate the value of digital learning. Both articles show that digital learning and new technologies have potential for advancing the quality of learning in our schools.
\end{abstract}

Keywords: Editorial, Pandemic, Augmented Reality, Digital literacy, Online learning

Since early 2020, learning technologies have been tested by millions of students, teachers, and parents from all levels of education throughout the globe. After decades of accumulated research and advancements within the educational technology field, it is hard to say whether this recent testing resulted in a positive outcome. For one thing, during the pandemic, many educators discussed learning losses, the inability of online learning to mimic real life learning environments, technological glitches, or the boring user interface of Zoom meetings. On the other hand, if the COVID-19 pandemic had happened 20-25 years ago, students would have completely lost touch with their peers and would not have attended any school for more than a year. Although the impact of more than a year of online education is not clear, this mode of instruction has presented numerous issues to think about, including the value of educational technology investments in the 21 st century.

In this issue, we have two interesting articles that will guide us as we evaluate the value of digital learning. The first article, authored by Yiting Han, is a literature review on the digital literacy practices of multilingual young adults and adolescents. The results of this review reveal that multilingual youth have many advantages. Of these, the most striking 
one is the development of global citizenship with the help of intercultural communication activities introduced in language classrooms. In the second article, Megan Tyson investigated augmented reality technologies and their effect on academic vocabulary gain. Students in this study reported that augmented reality activity was much more engaging, satisfactory, and overall, more effective in their vocabulary learning.

Both articles show that digital learning and new technologies such as augmented reality have great potential for advancing quality of learning in our schools. When, however, they are evaluated based on how well they can replicate traditional face-to-face learning, the experience the outcome will be disappointing.

Happy reading! 